\title{
Tecnicidade e identidades migrantes: contribuições de Martín-Barbero para pesquisas sobre migrações e usos sociais das mídias
}

\author{
Liliane Dutra Brignol \\ Doutora; Universidade Federal de Santa Maria; Santa Maria, RS, Brasil \\ lilianedb@yahoo.com.br
}

\section{Resumo}

A proposta do artigo é refletir sobre contribuições de Jesús Martín-Barbero em pesquisas sobre mídia e migrações contemporâneas, a partir de resgate da trajetória da própria pesquisadora, do grupo de pesquisa Comunicação em rede, identidades e cidadania (Universidade Federal de Santa Maria) e de outros estudos na área. Destaca-se a importância da perspectiva dos usos sociais das mídias e das mediações das identidades e tecnicidades como centrais para pesquisas que buscam entender transformações do lugar da comunicação e da cultura em contextos de convergência e diversidade.

\section{Palavras-chave}

Usos sociais. Mídias. Migrações. Mediações. Martín-Barbero.

\section{Introdução}

Este artigo é motivado pelas discussões realizadas no contexto do evento organizado na Universidade Federal do Rio Grande do Sul (UFRGS) pela Cátedra Jesús Martín-Barbero do Centro Internacional de Estudios Superiores de Comunicación para América Latina (CIESPAL) e pelo Programa de Pós-graduação em Comunicação e Informação da UFRGS, em novembro de 2017, em comemoração aos 30 anos do lançamento da obra Dos meios às mediações (MARTÍN-BARBERO, 2001), cuja primeira edição é de 1987. A proposta era reunir pesquisadores que tivessem sua trajetória de investigação atravessada por contribuições de Martín-Barbero e que pudessem dialogar sobre o impacto da publicação e 
da perspectiva das mediações, proposta por Martín-Barbero, nos estudos da comunicação no âmbito brasileiro e latino-americano.

Participar de uma mesa num evento de tributo a Jesús Martín-Barbero exigiu um exercício de reflexão, de memória e de afeto. Como o próprio pesquisador (MARTíNBARBERO, 2002a, p. 22) nos ensina, ao justificar seu interesse pelas matrizes populares, e recuperando Gramsci (19771 apud MARTÍN-BARBERO, 2002a, p. 25): “[...] somente investigamos de verdade o que nos afeta [...]". 0 percurso reflexivo do autor a respeito de sua própria trajetória, construído em muitos de seus textos, a exemplo de Martín-Barbero e Berkin (2017) e Martín-Barbero (2002a), nos faz entender o seu lugar enquanto cartógrafo mestiço (MARTÍN-BARBERO, 2002a, p. 10) e nos leva a percorrer com ele mapas sempre em construção das relações entre comunicação, cultura e política. Mapas que são desenhados a partir de inquietações genuínas, de experiências vividas e profundamente inspiradas pela história e pelas culturas da América Latina.

Difícil a tarefa do evento, de tantos outros tributos celebrados à terceira década da obra basilar de Martín-Barbero ${ }^{2}$ e que resgatamos neste artigo. Quantas chaves de leitura possíveis para recuperar a partir da extensa obra do pesquisador? Quantos caminhos inaugurados e provocados desde a aproximação a este pensador que é, a um só tempo, denso, contemporâneo, provocativo, questionador? Autor emblemático ao se pensar a comunicação na América Latina, para quem não há um único caminho para desbravar as relações entre comunicação, política e cultura, mas que, a partir de seus mapas noturnos, abriu possibilidades para tantos percursos de investigação.

Prova disto foi a diversidade de abordagens presentes nos relatos compartilhados no evento realizado na UFRGS. De modo geral, comungamos da ideia de que é difícil ficar indiferente à leitura de Martín-Barbero. Ele aparece, mesmo que não citado diretamente, como parte dos pressupostos teórico-metodológicos que guiam muitos percursos investigativos e, como pudemos perceber no evento-tributo, como parte da trajetória que constituiu o próprio campo da comunicação no Brasil e na América Latina.

Neste artigo, celebramos os 30 anos do lançamento da obra Dos meios às mediações ao mesmo tempo em que resgatamos o impacto e a atualidade da obra de Martín-Barbero. Temas que lhe são caros, como a cultura popular, a própria Latino-américa, o melodrama, a

\footnotetext{
${ }^{1}$ GRAMSCI, Antonio. Concepto de nacional popular. In: GRAMSCI, Antonio; SOLÉ TURA, Jordi. Cultura y literatura. Barcelona: Península, 1977. Apud Martín-Barbero (2002a).

${ }^{2}$ A exemplo da obra De los medios a las mediaciones de Jesús Martín Barbero, 30 años después, editada por Miquel de Moragas Spà, José Luis Terrón e Omar Rincón (2017) e uma edição especial da revista Matrizes (Universidade de São Paulo) com chamada aberta em 2017 (MATRIZES, 2018).
} 
telenovela, a juventude, a questão das audiências ou da recepção, a mestiçagem, a interculturalidade são pensados - como Martín-Barbero (2001, p. 280) diz magistralmente na obra que comemoramos seu aniversário de publicação - desde um outro lugar, o lugar das brechas, do consumo e do prazer.

Seus textos mais recentes (MARTÍN-BARBERO, 2014, 2015) nos provocam também a pensar sobre a convergência tecnológica como ambiente e ecossistema comunicativo; a convergência digital implicando nas apropriações dos meios comunitários e na conformação de um espaço cultural ibero-americano; o papel das mídias nos modos de produção e circulação do conhecimento, nas escolas públicas, no espaço doméstico e no lugar de trabalho; a comunicação cidadã e os movimentos sociais urbanos, as audiovisualidades e as hipertextualidades, entre outros tantos temas atuais e urgentes para pesquisadores da comunicação. Alguns dos quais, ajudam a ordenar o campo de questões que interessam discutir neste artigo, centrais para pesquisas sobre comunicação midiática e migrações a partir do enfoque dos estudos culturais latino-americanos.

Por meio da aproximação à perspectiva dos usos sociais das mídias, ao longo do texto, buscamos refletir sobre as contribuições de Martín-Barbero em pesquisas sobre mídia e migrações contemporâneas. Para tanto, em um primeiro momento, recuperamos a própria trajetória da pesquisadora, do grupo de pesquisa Comunicação em rede, identidades $e$ cidadania (UFSM e Conselho Nacional de Desenvolvimento Científico e Tecnológico - CNPq) e de outros estudos na área. Na segunda parte do texto, a discussão recai sobre as mediações das identidades e tecnicidades como centrais para pesquisas que buscam entender transformações do lugar da comunicação e da cultura em contextos de convergência e diversidade.

\section{Perspectiva dos usos sociais das mídias em uma trajetória de investigação}

Em minha trajetória, a leitura de Martín-Barbero remonta à época de graduação, como bolsista do então Programa de Educação Tutorial (PET), Coordenação de Aperfeiçoamento de Pessoal de Nível Superior (Capes), dos cursos de Comunicação Social (Jornalismo, Publicidade e Propaganda e Relações Públicas) da Universidade Federal de Santa Maria (UFSM), sob orientação da professora Veneza Mayora Ronsini. As leituras deram origem ao projeto de trabalho de conclusão de curso sobre usos sociais da internet por famílias santamarienses, intitulado Gaúchos na internet: da prosa ao email (BRIGNOL, 2001), em que 
as mediações da cotidianidade familiar, temporalidade social e competência cultural (MARTÍN-BARBERO, 2001) foram exploradas.

O interesse pelo tema das mídias e migrações começou no mestrado, no Programa de Pós-Graduação em Ciências da Comunicação da Universidade do Vale do Rio dos Sinos (Unisinos), onde desenvolvi a pesquisa Identidade cultural gaúcha nos usos sociais da internet: um estudo de caso sobre a Página do Gaúcho (BRIGNOL, 2004), sob orientação da professora Denise Cogo. 0 objetivo da pesquisa foi investigar as relações entre a internet e as identidades culturais gaúchas, de modo a discutir como questões identitárias atravessavam as dinâmicas de comunicação de um site pessoal. Para tanto, partia-se de uma compreensão de comunicação, cultura e identidades fundamentada na perspectiva dos estudos culturais, em diálogo com o aporte de Martín-Barbero, entre outros autores, de modo a entender a identidade gaúcha como mediação para usos sociais da internet, e, dialeticamente, sendo reconfigurada por meio de sua construção midiática.

Nesta pesquisa, o tema das migrações chegou a ser explorado, de modo secundário, com a análise de usos específicos da web acionados pela experiência de deslocamento para sujeitos nascidos no Rio Grande do Sul e que se encontravam longe do estado. A motivação da tese de doutorado, desenvolvida também na Unisinos, decorreu de pistas daí decorrentes, bem como da colaboração em outras investigações do grupo de pesquisa em que colaborava na época.

A tese intitulada Migrações transnacionais e usos sociais da internet: identidades $e$ cidadania na diáspora latino-americana (BRIGNOL, 2010) teve o objetivo de compreender as dinâmicas dos usos sociais da internet por migrantes latino-americanos, de maneira a refletir sobre o modo como questões identitárias impactam usos da rede mundial de computadores, demandando apropriações de seus ambientes comunicacionais e configurando estratégias para o acesso a condições diferenciadas de cidadania.

Para a realização da pesquisa, o estudo das migrações e dos usos sociais da internet partiu da aproximação aos contextos das cidades de Barcelona, capital da Catalunha, na Espanha, e de Porto Alegre, capital do Rio Grande do Sul, no Brasil. Ambas são fortemente marcadas pela presença da migração latino-americana, em dinâmicas urbanas, sociais e econômicas diversas, nas quais se pode perceber uma intensa confluência de culturas.

0 interesse central foi de conhecer usos sociais da internet por migrantes latinoamericanos, de maneira a refletir sobre a relação entre essas dinâmicas com o exercício de participações cidadãs e a experimentação de identidades (em suas diferentes perspectivas: 
migrante, étnica, nacional, latino-americana, cosmopolita), que conduzem à construção de modelos plurais de cidadania, o que vai além de direitos civis, políticos e sociais. A pesquisa ainda procurou discutir sobre o compartilhamento de experiências ligadas aos fluxos migratórios e a experimentação de múltiplos sentidos acionados pela identidade latinoamericana em apropriações da internet.

Metodologicamente, a investigação teve um caráter qualitativo, sendo organizada em três grandes eixos. No primeiro, desenvolvemos uma pesquisa teórica, com o aporte dos estudos culturais em aproximação a outras perspectivas teóricas (como os estudos migratórios e de análise de redes sociais), em que propomos uma aproximação ao universo das migrações e das identidades. Na pesquisa, a leitura de Martín-Barbero direcionou a compreensão do conceito de usos sociais das mídias, ao mesmo tempo em ajudou a entender o cenário complexo da América Latina e suas múltiplas culturas, identidades e temporalidades.

No segundo eixo, desenvolvemos uma pesquisa documental, por meio do levantamento de materiais de apoio sobre questões relacionadas às migrações e às Tecnologias da Informação e da Comunicação (TICs), o que permitiu situar melhor os contextos em que realizamos a investigação. Por último, para a pesquisa empírica desenvolvemos uma abordagem etnográfica, baseada na combinação de observação simples, observação online, questionários e entrevistas de relatos de histórias de vida com dezesseis sujeitos, oito em cada uma das cidades pesquisadas. Tal percurso permitiu conhecer as trajetórias pessoais dos migrantes, de modo a entender os sentidos construídos para a internet por meio de usos demandados por pertenças identitárias, com incidência na construção de versões próprias das experiências migratórias tematizadas em sites, blogs, fóruns de discussão e sites de redes sociais.

As reflexões suscitadas pelo resultado da pesquisa foram ampliadas em investigações posteriores e orientações desenvolvidas no âmbito do grupo de pesquisa Comunicação em rede, identidades e cidadania (UFSM/CNPq), em que são privilegiadas abordagens qualitativas de investigação, na análise dos processos de usos sociais das mídias, com temáticas relacionadas à construção de identidades e dinâmicas de participação cidadã por meio das TICs, especialmente por sujeitos em contexto de migração. Na sequência, destacamos algumas das reflexões teóricas acionadas por tais investigações, à luz das noções de usos sociais das mídias e de mediações. 


\section{Mapas das mediações e usos sociais das mídias}

Os mapas das mediações proposto por Martín-Barbero (2001, p. 20), no seu contínuo esforço de analisar as relações constitutivas entre comunicação, cultura e política, ajudam a refletir sobre "novos sentidos do social e novos usos sociais dos meios". Ao estudar os modos de uso como lugar de resistência (MARTín-BARBERO, 2002a, p. 186), o autor estabelece uma aproximação com a noção de táticas de Certeau (1994) para entender o domínio da técnica como terreno de luta das classes populares para se fazerem ouvir. Isso demanda olhar as tecnologias de comunicação em suas implicações culturais enquanto muito mais do que conjuntos de aparatos fechados em si mesmos, mas a partir de seus múltiplos e contraditórios modos de acesso, de aquisição e de usos.

Desta forma, em diálogo com uma perspectiva teórica que volta a atenção ao conceito de mediação, entendemos que os usos sociais das mídias são estabelecidos a partir de um conjunto de práticas e processos que interage não apenas na construção dos significados atribuídos à mídia, mas também nas formas como sujeito e tecnologia se relacionam. A multiplicidade de modos de apropriação das mídias (sobretudo da internet, em nossos estudos) é marcada pela capacidade de produção de sentido dos sujeitos, ainda que, muitas vezes, condicionada por restrições tecnológicas e pela desigualdade econômica e social no acesso, cada vez mais presentes em novas formas de exclusão em um contexto de centralidade da mídia na significação do mundo.

Com base na leitura de Martín-Barbero, pensamos, assim, que é a partir das mediações, em complexas dinâmicas de inter-relação ou articulação entre as esferas da produção e da recepção, que os sentidos vão sendo construídos. "É no deslocamento do interesse dos meios para o lugar onde é produzido o seu sentido, que são pensadas as dinâmicas dos usos sociais dos meios de comunicação, complexos e, muitas vezes, imprevisíveis." (BRIGNOL, 2010, p. 54-55). Assim, entendemos que bens simbólicos e mensagens são sempre transformados em seus usos sociais.

A presença generalizada dos meios e seus múltiplos usos sociais faz Martín-Barbero destacar, ao logo de sua vasta produção intelectual, um conjunto de mediações para entendermos a comunicação contemporânea. A experiência audiovisual e tecnológica (MARTÍN-BARBERO; REY, 2001) impõe novas formas de relação com a realidade, incluindo diferentes percepções do espaço e do tempo. A argumentação faz pensar sobre a emergência de dispositivos que implicam em mudanças nos vínculos sociais, ao lidarmos com os outros, cada vez mais, por meio das mediações do mundo da técnica. Obviamente, sem abandonar 
as práticas de comunicação interpessoal, em que o ritual da proximidade se mantém como dispositivo organizador, passamos a conviver com modelos comunicacionais mediados por tecnologias cada vez mais complexas.

Ao "entre-ver meios e mediações", portanto, o pesquisador sinaliza para a necessidade, em nossas perspectivas de investigação, de equilíbrio no papel atribuído a ambos. Como refletimos em texto anterior (BRIGNOL, 2015b), no prefácio da quinta edição de Dos meios às mediações, no seu décimo aniversário de lançamento, Martín-Barbero (2002a, p. 226) já enfatizava o papel dos meios de comunicação como espaço chave de "[...] condensación e intersección de la producción y el consumo cultural, al mismo tiempo que catalizan hoy algunas de las más intensas redes de poder.".

Nesta renovada trama comunicativa da cultura, ao deslocar o estudo da comunicação para o campo da cultura, é preciso voltar a atenção para as relações entre matrizes culturais e formatos industriais, como eixo diacrônico ou histórico, e lógicas de produção e competências de recepção e consumo, como um segundo eixo sincrônico (MARTÍN-BARBERO, 2001, p. 16). Neste novo mapa, ganham centralidade as mediações da socialidade, da institucionalidade, da ritualidade e da tecnicidade.

Resumidamente, podemos dizer que a socialidade, nas palavras de Martín-Barbero (2002a, p. 227), constitui o sentido da comunicação como questão de fins e não de meios. Trata-se da trama de relações cotidianas em que se constituem as práticas de comunicação. As ritualidades expressam as repetições, as rotinas e as inovações que se estabelecem enquanto "[...] gramáticas de acción - del mirar, del escuchar, del leer - que regulan la interacción entre los espacios tiempos de la vida cotidiana y los espacios y tiempos que conforman los medios." (MARTÍN-BARBERO, 2002a, p. 228). A institucionalidade afeta a regulação dos discursos, pelo Estado e pelos cidadãos, mediando a constituição do público e o reconhecimento cultural, enquanto a tecnicidade é compreendida como "competencia en el lenguaje" (MARTÍN-BARBERO, 2002a, p. 230-231), ou seja, como mais do que aparatos, mas como novas práticas e sedimentação de saberes.

É neste contexto que Martín-Barbero (2002a) situa a necessidade de estudo das tecnologias a partir da relação entre inovações culturais e seus usos sociais. 0 pensador denuncia a tendência à homogeneização por meio da uniformização tecnológica que desconsidera muitas das assimetrias entre os tempos de produção e de consumo, naquilo que aponta como uma não contemporaneidade entre tecnologias e usos, sobretudo em países da América Latina (MARTín-BARBERO, 2002a, p. 177-178). Ao mesmo tempo, 
reivindica a necessidade de deslocar o olhar das tecnologias em si mesmas para seus modos de acesso, de aquisição e de uso: “[...] desplazamiento de su incidencia en abstracto a los procesos de imposición y dependência, de dominación pero también de resistência, de resemantización y rediseño." (MARTÍN-BARBERO, 2002a, p. 177).

Este deslocamento é provocativo para o percurso de nossas pesquisas em comunicação, pois exige complexificar a compreensão dos imbricamentos entre sociedade e meios, sujeitos e tecnologias. De acordo com Martín-Barbero (2002a, p. 186), para romper com o deslumbramento pela tecnologia, é preciso interrogá-la desde o lugar das apropriações e dos usos das classes populares. "El domínio de la técnica se convierte así en un terreno inmediato de lucha, de la lucha por hacerse oír [...]" (MARTÍN-BARBERO, 2002a, p. 187), a exemplo do que o pesquisador aponta como a produção de programas de rádio por comunidades migrantes na cidade de Lima, como forma de criar um espaço de identificação e reconhecimento em torno das próprias experiências dos sujeitos.

Parte-se, no entanto, do entendimento de que as tecnologias não são simples ferramentas transparentes, pois não se deixam usar de qualquer modo, sendo atravessadas por sentidos, lógicas e estruturas que trazem implicadas relações desiguais de acesso, de competências e de usos. Com base em Martín-Barbero, entendemos que, se a apropriação não é possível enquanto estratégia, que seja ao menos como tática: “[...] en el sentido que le da Michel de Certeau: el modo de lucha de aquél que no puede retirarse a su lugar y se ve obligado a luchar en el terreno del adversario." (MARTÍN-BARBERO, 2002a, p. 189-190).

\section{Mediações da tecnicidade e identidades em pesquisas sobre mídia e migrações}

Em mais uma atualização de seu mapa sobre as matrizes comunicativas da cultura, Martín-Barbero (2009) enfatiza as medições das identidades e das tecnicidades como essenciais para se pensar a complexidade das relações constitutivas da comunicação na cultura, em contextos em que os sentidos de tempo e espaço passam por profundas transformações em função dos fluxos informativos e comunicacionais e das dinâmicas de deslocamentos migratórios: 
No meu novo mapa temos: tempo, espaço, migrações, fluxos. Então as mediações passam a ser transformação do tempo e transformação do espaço a partir de dois grandes eixos, ou seja, migrações e fluxos de imagens. De um lado, grandes migrações de população, como jamais visto. De outro, os fluxos virtuais. Temos que pensá-los conjuntamente. Os fluxos de imagens, a informação, vão do norte ao sul, as migrações vão do sul ao norte. E há a compressão do tempo, a compressão do espaço e é aí que eu recomponho as duas mediações fundamentais hoje: a identidade e a tecnicidade. (MARTÍN-BARBERO, 2009, p. 14).

Com o protagonismo das tecnologias, nos colocamos diante do desafio de investigar como se dinamizam as apropriações das mídias por sujeitos que vivem a experiência do deslocamento, em dinâmicas transnacionais que intensificam o convívio com as diferenças culturais. Os migrantes, como consumidores (e, em alguns casos, produtores) de mídias evidenciam um conjunto de práticas, de comparações, de lógicas múltiplas de reconhecimento que nos provocam a pensar a partir de algumas das categorias sinalizadas na perspectiva teórica das mediações comunicativas da cultura. Neste percurso, a busca de conceitos articulados por Martín-Barbero nos leva ao afastamento de uma perspectiva determinista, por meio da qual as tecnologias trariam sempre a imposição de mudanças, desconsiderando a relação com as práticas culturais de diferentes grupos. Ao mesmo tempo, as provocações teóricas do pesquisador ajudam a lançar perguntas sobre as reconfigurações das identidades e das culturas a partir das apropriações das diferentes tecnologias.

Martín-Barbero (2014) nos mobiliza, assim, a refletir as relações entre tecnologia e cultura a partir da América Latina, num afastamento do que ele aponta (recuperando Raymond Williams ${ }^{3}$ ) como uma nefasta combinação entre determinismo tecnológico e pessimismo cultural. Neste sentido, o foco do nosso trabalho de pesquisa tem sido na apropriação das tecnologias por coletivos migrantes como possibilidade de participação social, de experimentação transnacional e, em alguns casos, de transformação social a partir de práticas cidadãs:

[...] se a revolução tecnológica das comunicações agrava o fosso das desigualdades entre setores sociais, entre culturas e países, ela também mobiliza a imaginação social das coletividades, potencializando suas capacidades de sobrevivência e de associação, de protesto e de participação democrática, de defesa de seus direitos sociopolíticos e culturais e de ativação de sua criatividade expressiva [...] (MARTínBARBERO, 2014, p. 19).

\footnotetext{
${ }^{3}$ Martín-Barbero (2014) faz referência, em epígrafe do artigo Diversidade em convergência, à citação de Raymond Williams (1921 - 1988), em que o teórico e crítico cultural, considerado um dos fundadores dos estudos culturais britânicos, fala dos limites do pensamento dualista acerca das relações entre cultura e tecnologia, especialmente em referências às transformações da televisão. Romper este dualismo, entre conservadores culturais e entusiastas das tecnologias, é assumido como desafio a que se propõe Martín-Barbero.
} 
Daí a importância de se entender os meios de comunicação a partir da luta contra o pensamento único, por meio do esforço de investigação de suas diferentes apropriações individuais e coletivas. Assim, não falamos da internet como uma tecnologia única, que oferece possibilidades de comunicação radicalmente novas e libertadoras, mas como um ambiente comunicacional que deriva da consolidação de múltiplas tecnologias, cujos sentidos, marcados por uma estrutura que nunca é neutra, podem ser transformados a partir de seus efetivos usos sociais.

Como discorre Martín-Barbero (2006, p. 54), “[...] é o próprio lugar da cultura na sociedade que muda quando a mediação tecnológica da comunicação deixa de ser meramente instrumental para espessar-se, adensar-se e converter-se em estrutura.". Desta forma, estudar as dinâmicas de comunicação em rede exige, como ensina o autor, pensar a tecnologia não só como novidade dos aparatos, mas como novos modos de linguagem e percepção, novas sensibilidades e escrituras. Assim, as apropriações diversas e nem sempre previsíveis das tecnologias podem configurar novas formas de saber e maneiras inventivas de intervenção social.

Em alguns de seus textos mais recentes (MARTíN-BARBERO, 2006, 2014, 2015), reforça a importância destas duas instâncias essenciais que impactam o modo como estamos no mundo hoje: a revitalização das identidades e a revolução das tecnicidades. Em uma aproximação ao pensamento de Milton Santos (2002), ao apontar as simultâneas possibilidades e perversidades da globalização, Martín-Barbero (2014) vê a diversidade cultural como lugar de resistência, negociação, interação e potencial de transformação diante dos processos de globalização homogeneizantes, pois, como indica, "[...] o que reativa hoje as identidades como motor de luta é inseparável da demanda de reconhecimento e de sentido." (MARTÍN-BARBERO, 2014, p. 24).

A partir da concepção de mediações, identificamos que, apesar dos limites tecnológicos e das desigualdades sociais e econômicas enfrentadas no contexto das migrações, há uma diversidade de apropriações das tecnologias da mídia marcadas pela relação com as próprias situações de vida dos sujeitos migrantes e, muitas vezes, demandadas por suas experiências identitárias. É a própria condição de migrante que produz, muitas vezes, modalidades particulares de usos midiáticos (BRIGNOL, 2010), centrados, principalmente, nas relações com o país de nascimento e na criação de redes de partilha e convivência entre migrantes que dividem uma experiência de deslocamento comum (COGO; HUERTAS BAILÉN; GUTIÉRREZ, 2008). 
0 próprio conceito de identidade precisa ser pensando em função do impacto das transformações culturais com a dinamização dos fluxos migratórios:

\begin{abstract}
Até pouco tempo, falar de identidade era falar de raízes, isto é, de costumes e território, de tempo longo e de memória simbolicamente densa. Disso e somente disso estava feita a identidade. Mas falar de identidade hoje implica também - se não quisermos condená-la ao limbo de uma tradição desconectada das mutações perceptivas e expressivas do presente - falar das migrações e mobilidades, de redes e de fluxos, de instantaneidade e de fluidez (MARTÍN-BARBERO, 2006, p. 61).
\end{abstract}

Em nossas pesquisas, buscamos pensar nas identidades, ainda, a partir do modo como são contadas, narradas, reconstruídas pelas experiências e através da memória dos sujeitos que vivem em seu cotidiano essas transformações das culturas e de suas formas de reconhecimento. Consideramos a possibilidade de construir narrativas identitárias por meio do processo duplo de contar-se e perceber a alteridade, o que passa, em grande medida, por construções midiáticas:

Contar significa tanto narrar historias como ser tenidos en cuenta por los otros. Lo que entraña que para ser reconocidos necesitamos contar nuestro relato, pues no existe identidad sin narración ya que ésta no es sólo expresiva sino constitutiva de lo que somos. Para que la pluralidad de las culturas del mundo sea políticamente tenida en cuenta es indispensable que la diversidad de identidades pueda ser contada, narrada. (MARTÍNBARBERO, 2002b, p. 8).

Ao compreender as identidades como narrativas (BHABHA, 1998), marcadas pela experiência de deslocamento, devemos considerar todos os elementos que podem participar da construção desses relatos, perpassados por uma diversidade de linguagens, códigos e sentidos, cada vez mais diversos - o que pode levar tanto a uma adequação a modelos homogêneos e estereotipados, quanto oferecer a possibilidade de subverter esses mesmos modelos e dar visibilidade à pluralidade de narrativas identitárias. Movimento que pudemos observar ao nos aproximarmos da especificidade dos usos sociais das mídias, em estudos empíricos, com migrantes de diferentes nacionalidades. A própria América Latina pode ser considerada, como lembra Martín-Barbero (2002b), como um laboratório de identidades dinâmica potencializada quando essas identidades entram em contato com outras diferenças e são ressignificadas na diáspora (HALL, 2003). 


\title{
5 Migrantes-cibernautas?
}

A diversidade cultural, fonte de reflexão e problematização teórica em toda a trajetória de Martín-Barbero, é retomada como um dos principais pontos desde onde estudar os processos, as práticas e os meios de comunicação hoje (MARTíN-BARBERO; BERKIN, 2017). Nesta proposição, migrantes e cibernautas/internautas são duas categorias indicativas de modos de ser e estar no mundo contemporâneo muito mais próximas do que faz crer uma razão dualista que opõe deslocamentos entre territórios e fluxos comunicacionais. Trata-se da instância em que, segundo o autor, as urbanias e as cidadanias se entrelaçam:

\begin{abstract}
Las experiencias y narrativas del inmigrante se entremezclan cada día más densamente con las de los cibernautas. Millones de desplazados y emigrantes - dentro y fuera de cada país- practican la ciudad que habitan escribiendo relatos en el chat o en hipertextos de la web, desde los que individuos y comunidades se comunican con sus familiares que quedan al otro lado del mundo. Y ello mediante la circulación de historias y de imágenes en las que cuentan, se cuentan, para seguir contando entre la gente y para ser tenidos en cuenta por los que sobre ellos toman decisiones que les afectan. (MARTÍN-BARBERO, 2015, p. 27).
\end{abstract}

Estas aproximações nos ajudam a investir, no ponto de vista das pesquisas sobre mídia e migrações, nas relações entre os fluxos informativos, de imagens e comunicacionais, associados às lógicas de mobilidade e deslocamentos migrantes. Ambos os movimentos impactam, segundo Martín-Barbero (2009), as dinâmicas de tempo e espaço. Ser e estar no mundo hoje, diante das mutações tecnoculturais apontadas pelo autor, implica em deslocarse por entre hipertextos e por culturas.

Neste percurso, migrantes e internautas funcionam como figuras emblemáticas que provocam rupturas na ordem estabelecida, o que pode levar, em alguns casos, ao estranhamento e ao medo. A ameaça migrante, vista sob esta perspectiva, desestabiliza ao instaurar a incerteza sobre a pureza do que está dentro, tal como também observa Appadurai (2009) ao analisar as violências crescentes contra minorias como ilusório movimento de defesa de identidades que se pensam fixas. Da mesma forma, os novos fluxos informativos, em suas lógicas audiovisuais e hipertextuais, podem representar uma ameaça ao operar saberes que escapam ao controle da escola, da família e de outras instituições tradicionais. 
Así como los flujos de emigrantes ocasionan desórdenes sociales y políticos en la ciudad, también los flujos de información y de imágenes, los lenguajes y las escrituras virtuales introducen el caos en la ciudad letrada y escolar, pues también estos desbaratan las autoridades y las jerarquias [...] (MARTÍN-BARBERO, 2015, p. 26).

Para além desta polarização redutora, Martín-Barbero provoca a olhar as tecnologias digitais a partir das transformações sociais implicadas em suas múltiplas apropriações, que podem levar a uma descentralização das lógicas de produção e circulação do saber. No que identifica como uma redução das fronteiras entre razão e imaginação, saber e informação, arte e ciência, saber experto e experiência profana (MARTÍN-BARBERO, 2015, p. 27), podemos localizar a aproximação das experiências dos migrantes com a dos comunicantes (OROZCO GÓMEZ, 2011) em mídias digitais.

Assim, ao se apropriarem criativamente das tecnologias da mídia e ao ocuparam as ambiências comunicacionais digitais como forma de disputa por visibilidade, migrantesinternautas (ao aproximar as duas categorias segundo a lógica proposta por MartínBarbero) tensionam as práticas, põem em contato as diferenças e evidenciam demandas por participação, reconhecimento e interculturalidade. É o que temos evidenciado em nossas pesquisas sobre usos sociais da internet por migrantes latino-americanos e, mais recentemente, em investigações sobre novos fluxos migratórios para o Sul global, com a presença mais significativa de coletivos senegaleses no Brasil, por exemplo (BRIGNOL, 2015a).

De um modo geral, os múltiplos usos sociais das mídias por migrantes assumem sentidos táticos de participação social, de construção de narrativas de si, de manutenção de vínculos, de construção de redes de apoio, de ressignificação da experiência diaspórica e de cidadania migrante. Assim, propomos pensar a internet inserida em um contexto complexo, passando a ser problematizada desde as tensões entre inovações da ordem tecnológica e as identidades dos sujeitos migrantes que se apropriam de seus espaços comunicacionais. Neste percurso, a diversificação dos usos da internet tensionados pelas experiências migratórias está associada a uma redefinição do próprio conceito de cidadania migrante, implicando-nos a pensar na possibilidade crescente de os sujeitos assumirem autonomia e protagonismo no percurso que constroem para se informar, assim como na produção de formas de comunicação alternativas e plurais que fazem circular outros sentidos sobre as migrações transnacionais. 


\section{Considerações finais}

O contexto das migrações, ao colocar em contato diferenças culturais e dinamizar situações de diversidade, lança luz a várias questões sobre identidades, interculturalidade, consumo e produção transnacional de mídia, servindo como um campo de observação riquíssimo para a comunicação.

Em nossas pesquisas, investigamos os usos sociais das mídias por migrantes, sobretudo, a partir das mediações das identidades e tecnicidades. Partindo da compreensão da dimensão estrutural da mediação tecnológica, buscamos, portanto, entender como as tecnologias da comunicação assumem um papel central no cotidiano dos migrantes.

No grupo de pesquisa Comunicação em rede, identidades e cidadania, nos vinculamos à perspectiva dos usos sociais das mídias, com o aporte de Martín-Barbero, o que leva à construção de um percurso teórico-metodológico baseado em uma abordagem qualitativa, com foco nos procedimentos da observação, da observação participante e da busca pelo encontro com os sujeitos migrantes, em seus relatos, nas suas experiências cotidianas e na interpretação a partir de suas práticas e processos comunicativos.

Como buscamos construir neste artigo, as múltiplas leituras possíveis de MartínBarbero ajudam no desafio da reflexão sobre por onde pensar as dinâmicas de transformação do lugar da cultura em nossas sociedades globalizadas. Sociedades atravessadas pelos fluxos de pessoas, de imagens e de práticas comunicacionais merecem ser observadas pelo olhar curioso de quem se deixa afetar pelas potencialidades das tecnologias da mídia, sem abandonar a crítica necessária para com suas determinações e limites.

Aprendemos, com Martín-Barbero, a ver com os outros (MARTín-BARBERO; BERKIN, 2017), ao perceber o impacto da experiência da América Latina nas rupturas epistemológicas que permeiam sua produção intelectual. Neste percurso, o local e o global se tocam, os fluxos migratórios e informacionais tensionam nosso modo de ser e estar no mundo, o migrante e o internauta se aproximam, indicando situações em que a convergência digital pode evidenciar exclusões ou provocar fissuras rumo a uma comunicação intercultural.

\section{Referências}

APPADURAI, Arjun. 0 medo ao pequeno número: ensaio sobre a geografia da raiva. São Paulo: Iluminuras, 2009. 
BHABHA, Homi. O local da cultura. Belo Horizonte: Ed. UFMG, 1998.

BRIGNOL, Liliane Dutra. Gaúchos na internet: da prosa ao email. 2001. Trabalho de Conclusão de Curso (Graduação em Comunicação Social - Jornalismo) - Universidade Federal de Santa Maria, Santa Maria, 2001.

BRIGNOL, Liliane Dutra. Identidade cultural gaúcha nos usos sociais da internet: um estudo de caso sobre a Página do Gaúcho. 2004. Dissertação (Mestrado em Ciências da Comunicação) - Programa de Pós Graduação em Ciências da Comunicação, Universidade do Vale do Rio dos Sinos, São Leopoldo, 2004.

BRIGNOL, Liliane Dutra. Migrações transnacionais e usos sociais da internet: identidades e cidadania na diáspora latino-americana. 2010. Tese (Doutorado em Ciências da Comunicação) - Programa de Pós-Graduação em Ciências da Comunicação, Universidade do Vale do Rio dos Sinos, São Leopoldo, 2010.

BRIGNOL, Liliane Dutra. Recepção midiática e migração: a perspectiva dos usos sociais da mídia na investigação sobre o Brasil imaginado por migrantes transnacionais. In: BRIGNOL, Liliane Dutra; BORELLI, Viviane. Pesquisa em recepção: relatos da II Jornada Gaúcha. Santa Maria: Facos/UFSM, 2015b.

BRIGNOL, Liliane Dutra. Usos sociais das TICs em dinâmicas de transnacionalismo e comunicação migrante em rede: uma aproximação à diáspora senegalesa no sul do Brasil. Comunicação, mídia e consumo, São Paulo, v. 12, n. 35, p.89-109, 2015a.

CERTEAU, Michel de. A invenção do cotidiano: artes de fazer. Petrópolis: Vozes, 1994.

COGO, Denise; HUERTAS BAILÉN, Amparo; GUTIÉRREZ, Maria (Coord.). Migraciones transnacionales y medios de comunicación: relatos desde Barcelona e Porto Alegre. Madrid: Los Libros de la Catarata, 2008.

HALL, Stuart. Da diáspora: identidades e mediações culturais. Belo Horizonte: Ed. UFMG; Brasília: UNESCO, 2003.

MARTÍN-BARBERO, Jesús. As formas mestiças da mídia. Pesquisa FAPESP, n. 163, p. 10-15, set. 2009.

MARTÍN-BARBERO, Jesús. Desde dónde pensamos la comunicación hoy. Chasqui, Quito, n. 128, p. 13-29, 2015.

MARTÍN-BARBERO, Jesús. Diversidade em convergência. MATRIZes, São Paulo, v. 8, n. 2, p. 15-33, 2014.

MARTÍN-BARBERO, Jesús. Dos meios às mediações: comunicação, cultura e hegemonia. Rio de Janeiro: Ed. UFRJ, 2001.

MARTÍN-BARBERO, Jesús. La globalización en clave cultural: una mirada latinoamericana. In: 2001 EFECTOS GLOBALISMO Y PLURALISMO, 2002, Montreal. Actes... Montreal, 2002b. 
MARTÍN-BARBERO, Jesús. Oficio de cartógrafo: travesías latino-americanas de la comunicación en la cultura. Santiago del Chile: Fondo de Cultura Económica, 2002a.

MARTÍN-BARBERO, Jesús. Tecnicidades, identidades, alteridades: mudanças e opacidades da comunicação no novo século. In: MORAES, Denis. (Org.). Sociedade midiatizada. Rio de Janeiro: Mauad, 2006.

MARTÍN-BARBERO, Jesús; BERKIN, Sarah Corona. Ver con los otros: comunicación intercultural. Ciudad de México: Fondo de Cultura Económica, 2017.

MARTÍN-BARBERO, Jesús; REY, Germán. Os exercícios do ver: hegemonia audiovisual e ficção televisiva. São Paulo: Senac, 2001.

MATRIZES. São Paulo: USP, v. 12, n. 1, jan./abr. 2018.

MORAGAS SPÀ, Miquel de; TERRÓN, José Luis; RINCÓN, Omar (Ed.). De los medios a las mediaciones de Jesús Martín Barbero, 30 años después. Bellaterra: InCom-UAB, 2017.

OROZCO GÓMEZ, Guillermo. La condición comunicacional contemporánea: desafíos latinoamericanos de la investigación de las interacciones en la sociedad red. In: JACKS, Nilda (Org.). Análisis de la recepción en América Latina: un reencuento con perspectivas a futuro. Ecuador: CIESPAL, 2011.

SANTOS, Milton. Por uma outra globalização: do pensamento único à consciência universal. Rio de Janeiro: Record, 2002.

\title{
Technicity and migrant identities: Martín- Barbero's contributions to research on migration and social uses of media
}

\begin{abstract}
This article proposes a reflection on Jesus Martín-Barbero's contributions to research on contemporary media and migration taking as starting point this author's own trajectory, that of the research group Network Communication, identities and citizenship (Universidade Federal de Santa Maria) and other studies in the area. It highlights the importance of observing the social uses of media as well as the mediations of identities and technicities as central to research seeking to understand the transformation of the place of communication and culture in the context of convergence and diversity.
\end{abstract}

\section{Keywords}

Social uses. Media. Migration. Mediations. Martín-Barbero. 